\title{
A STUDY OF DWARFNESS IN WHEAT ACCOMPANIED BY UNEXPECTED RATIOS
}

\author{
L. R. WALDRON \\ North Dakota Agricultural Experiment Station, Agricultural College, North Dakota
}

Received December 13, 1923

TABLE OF CONTENTS

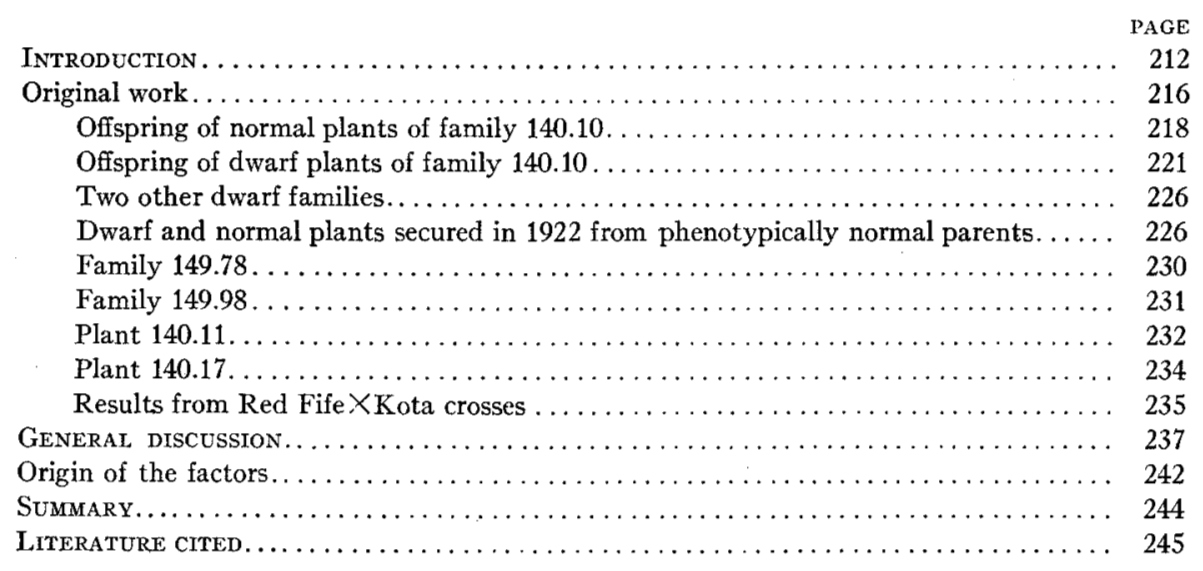

INTRODUCTION

Plants markedly deficient in height may suddenly appear and their genetical import claims attention. Plants of this nature have been noted several times in the cereals and also in other groups of cultivated plants. Cook (1915) has classified plants of deficient stature into dwarfs and brachytes. He says, in effect, that a dwarf is a plant markedly deficient in stature and having parts correlated with each other as in the normal plant. A brachytic plant, on the other hand, is one possessing a diminished vertical axis, caused by shortening of the internodes, without a corresponding reduction of other parts. He includes in the brachytic class, for example, most of the "dwarf" or "bush" varieties of peas, beans, squashes and tomatoes, the phenomenon being found in other groups of plants also. 
Striking and excellent examples of brachytic dwarfs ${ }^{1}$ are found in maize reported upon by different investigators. EAST and HAYES (1911) described such a dwarf, having a height of only 18 inches, in a commercial strain of Stowell's Evergreen sweet corn. The leaves were broad but short, while the plant had the appearance of having been telescoped down upon itself. Satisfactory genetical data on this plant were not secured. Dwarf plants of a brachytic type were found by EMERson (1911) in three families of maize. Families coming from self-pollinated phenotypically normal plants contained dwarf and normal plants in the ratio of 24 to 107. Later studies by EMERSON and EMERson (1922) revealed the character inherited as a simple recessive to normal.

Kempton (1920) crossed two varieties of maize, designated Chinese and Algerian. In the $F_{2}$ generation about one-fourth of the plants were of a pronounced dwarf type. When these were selfed or intercrossed, brachytic dwarfs were uniformly produced. Crosses of these dwarfs with normal plants produced normal $F_{1}$ offspring with a simple 3-to-1 segregation in the succeeding generation, the dwarf form being simply recessive. In this case dwarf plants appeared when two very distinct varieties of maize were crossed, but as they also appear in self-fertilized commercial strains, this fact evidently has but little bearing upon the origin of the factor. Further work by KEMPTON (1923) has revealed another maize form, of diminished stature, which he considers a true dwarf, not brachytic. Crosses between his two dwarf forms result in entirely normal plants in the frst generation. The genes for the two characters of dwarfness must be located in separate chromosomes.

Emerson (1916) has made a detailed study of bush and twining beans, from a genetical standpoint. He states that the bush bean differs from the twining bean only in its habit of growth. The bushtbean growth is determinate while that of the pole bean is indeterminate. The bush habit, in contrast to the twining habit of pole beans, is conditioned by a smaller number of internodes and also by a relatively small mean internode length. This latter condition evidently has not been brought about by a general shortening of the axis, but rather by a cessation of axial growth early in the period of growth-rate acceleration, before the period of maximum internode-length formation:

Evidently dwarfness in maize, instanced in the examples cited, belongs to a somewhat different category than the dwarf habit of beans. KEMPToN

\footnotetext{
${ }^{1}$ While recognizing the validity of the classification laid down by Cook, it is more tenable to recognize brachytic plants as dwarf plants of limited character. This article deals with brachytic plants but they will be referred to as dwarf plants or dwarfs.
}

GeNETrCS 9: My 1924 
found that inheritance of dwarfness in maize was due to a single Mendelian factor with normal height dominant. Likewise, EMERson found the same method of inheritance in bush and twining beans, and he reviews the work of different investigators who have secured similar results working with dwarf varieties of peas, sweet peas, tomatoes and maize. In investigations with the two types of beans, bush and twining, Tschermak (1912) found a complicated method of inheritance. In order to explain the results he assumed the existence of several factors and also the possible formation of unequal numbers of gametes and of zygotes.

Vilmorin (1913) discussed the inheritance of "dwarf" plants found in two varieties of wheat. These plants were about 80 percent of the normal height of the variety from which they were obtained. Seed of dwarf and normal plants was planted for a number of years. Normal plants always produced normal offspring while dwarf plants produced dwarf and normal offspring in the ratio of about $1: 2.35$. It is not possible to gather from his paper whether a higher proportion of offspring from dwarf plants failed to come to maturity than off spring from normal plants. His failure to secure homozygous dwarf plants is ascribed by him to the failure of the zygotes to survive. In other words, he evidently was working with lethal factors, similar to the classical case of the yellow coat color of mice described by Cúnot and others. The dwarf wheats of Vilmorin differ from the dwarf maize plants of KEMPTON and others already discussed in this paper and differ also from the dwarf wheat and oats to be considered later.

Mryazawa (1921) crossed two varieties of barley, finding in the $F_{2}$ generation one dwarf plant in a total of 96 . This dwarf, like that found by VILMORIN, was evidently an intermediate heterozygote differing by one factor from the normal plant. When the young seedlings were given sufficient protection, small and quite sterile dwarfs developed, evidently homozygous. When the barley cultures were well cared for so that the maximum number of plants developed, a reasonable approximation to the $3: 1$ ratio was secured.

Comparing the results of Mryazawa with those of Vilmorin, one finds the two cases similar, but in the case of barley, lethal factors exerted much less influence than in the case of the wheat. Quite certainly the presence of dwarf and sterile wheat plants in VILMORIN's cultures would have been noticed. The results of Mryazawa are apparently intermediate in a way between those of VILMORIN and the results secured by EMERSon with dwarf maize plants. In the case of the dwarf maize it was possible to secure seed from the homozygous forms and produce homozygous offspring in turn. One hesitates to say that the factors bringing about dwarfness in maize are 
lethal in character, although it is obvious that the dwarf maize plant has little chance to compete with the normal plant.

Cases have been found in wheat and oats which are apparently entirely comparable with those found by EMERson and others in maize, that is, plants occur which are strictly dwarf in character and evidently homozygous. The first worker to report dwarf wheat plants was FARRER (1898), working in Australia. He gives an extended description of the plants, quoted by WARBURTON (1919). He speaks of the plants as "grass clumps," thus indicating the abundance of stools which they develop, the plants only occasionally producing heads. He harvested grain from some of the dwarf plants, the offspring consisting of both normal and dwarf plants, while in one instance the entire offspring consisted of dwarfs. He found the plants appearing only when different varieties of common wheats were crossed, none appearing when one of the parent varieties was Triticum durum or T.turgidum. The abnormal plants nearly always appeared in the $F_{2}$ generation; in one instance the $F_{1}$ plants were dwarf, although here one of the parents was the result of a recent hybridization and was probably heterozygous in character. From the information furnished by FARRER it is not possible to determine much about the Mendelian behavior of the dwarf plants.

Plants similar to those found by FARRER were reported by RICHARDSON (1913) from Victoria where he found 28 dwarf plants in a total population of 15,800 of hybrid parentage. The dwarf plants had a height of about nine inches. Less than 50 percent formed heads and only nine percent of them produced grain.

NeEthling (1917), by crossing two common wheats of normal height, secured only normal plants in the $F_{1}$ generation; in the $F_{2}$ generation, in the one case where data are given, 8 dwarfs appeared in a total of 31 plants. He considered dwarfness to be brought about by a single recessive factor. It is not explained how such a factor could have been carried in one of the two normal parents without an accompanying inhibiting factor. Aside from the single $F_{2}$ result for which data are given, his figures are rather more favorable to a two-factor hypothesis, including an inhibiting factor, than to the one-factor hypothesis suggested.

CUtLer (1919) reported dwarf wheat plants occurring in head-rows selected from Marquis wheat. Evidently dwarf plants were found in more than one head-row and their occurrence was noted during three years, 1914 to 1916. Cutler states that the plants of lowest stature, about nine inches tall, produced a high percentage of dwarf plants, in some cases 100 percent. Extracted normal plants produced only normal offspring, 
while intermediate plants produced dwarfs, intermediates and normals in the ratio of $1: 2: 1$. No data are given in the article to support these statements. Dwarf plants were found in other varieties, according to Cutler, the variety Red Fife being specifically mentioned. It is quite certain that the dwarf plants observed by CUTLER became manifest as a result of field crosses of Marquis with other varieties, as it is stated that aside from the appearance of dwarfs, variable characters were present relative to color of chaff, beardedness, shape of kernel, etc. It is reasonable to suppose that the dwarfs which appeared in other varieties likewise made themselves known as a result of field crossing.

WARBURTON (1919) found dwarf oat plants in the Victory variety which were entirely comparable to the dwarf wheat plants discussed above. In one head-row of Victory oats grown at Aberdeen, Idaho, 40 percent of the plants were dwarf in character. These measured not over nine inches in height. Seed saved from the dwarf plants was given to two plant breeders for growing. The complete results indicated that the dwarf character was due to a single Mendelian factor. The 3:1 ratio was approximated very closely. WARBURTon does not indicate that other characters besides dwarfness were concerned, and he does not suggest that the dwarfs which produced dwarf offspring were the result of a field cross.

SAX (1921) crossed Bluestem and Amby wheats, planting $52 \mathrm{~F}_{1}$ seeds of reciprocal crosses. Apparently the entire $F_{1}$ offspring was strictly dwarf, producing no fertile culms. Conditions here are entirely different from those reported in most other cases.

Stanton (1923) has recently reported two cases of dwarf oat plants appearing in the $F_{4}$ and $F_{6}$ generation, of two crosses. In one instance dwarfness proved to be heterozygous in a monohybrid ratio, while in the other case one entire progeny may have been dwarf, comparable with the dwarf hybrid wheat of SAX.

\section{ORIGINAL WORK}

In 1918 the writer made certain crosses between a variety of wheat resistant to Puccinia graminis, later named Kota (WALDRON and CLARK 1919), and certain rust-susceptible varieties. All wheats were of the common type, Triticum vulgare. While dwarfs appeared in hybrid families of different varieties of the susceptible wheats, those occurring from the combination Marquis $\times$ Kota were studied in greatest detail. Dwarf and normal plants are shown in figure 1.

In 1919, four $\mathrm{F}_{1}$ plants are to be noted resulting from Marquis-Kota crosses of 1918. Three of the plants measured $90 \mathrm{~cm}$ in height and one 


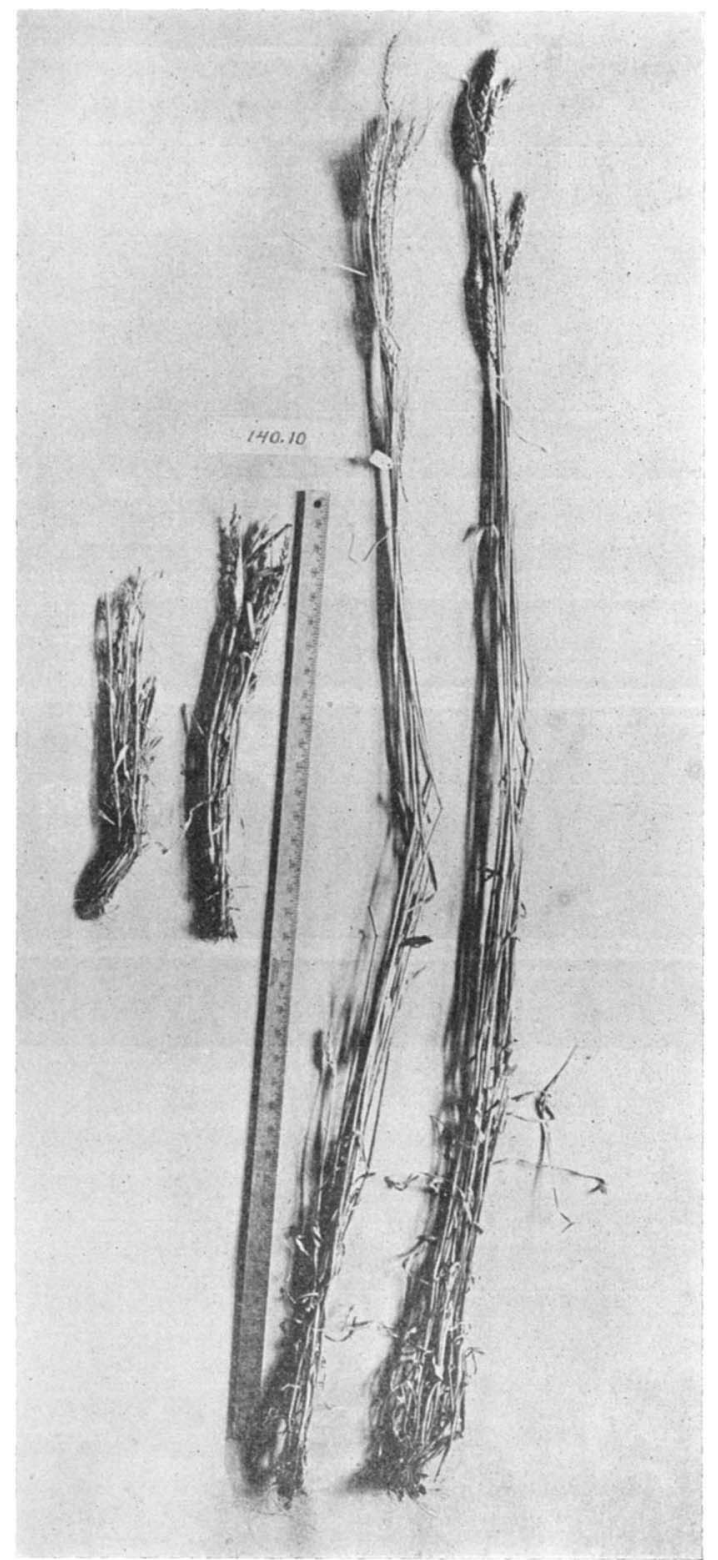

Figure 1.-Two plants each of dwarf and normal wheat from family 140.10. The taller dwarf is plant $\mathbf{1 5 2 . 8}$. 
measured 95. In 1920 the four plants produced $\mathrm{F}_{2}$ offspring as shown in table 1.

TABle 1

Normals and dwarfs of four Marquis-Kota hybrids.

\begin{tabular}{l|c|c|c}
\hline $\begin{array}{c}\text { PEDIGREE } \\
\text { NUMBERS }\end{array}$ & NORMALS & DWARFS & \multicolumn{1}{|l}{ RATIO } \\
\hline 140.7 & 20 & 5 & $4.0: 1$ \\
140.10 & 96 & 18 & $5.3: 1$ \\
140.11 & 53 & 15 & $3.5: 1$ \\
140.17 & 60 & 9 & $6.7: 1$ \\
\hline Total & 229 & 47 & $4.9: 1$ \\
\hline
\end{tabular}

This ratio does not approximate a $3: 1$ ratio and doubt arises immediately as to the simplicity of the dwarf factor carried in the parental form. In crosses between Red Fife wheat and Kota, dwarfs also appeared in the $\mathrm{F}_{2}$ generation in 1920 as shown in table 2.

TABLE 2

Normals and dwarfs of nine Red Fife-Kota hybrids.

\begin{tabular}{c|c|c|c}
\hline $\begin{array}{c}\text { PEDIGREE } \\
\text { NUMBERS }\end{array}$ & NORMALS & DWARFS & \multicolumn{1}{|c}{ RATIO } \\
\hline 140.14 & 38 & 5 & $7.6: 1$ \\
140.15 & 19 & 2 & $9.5: 1$ \\
140.20 & 11 & 4 & $2.8: 1$ \\
140.21 & 85 & 12 & $7.1: 1$ \\
140.22 & 35 & 1 & $35.0: 1$ \\
140.27 & 30 & 5 & $6.0: 1$ \\
140.29 & 23 & 0 & -1 \\
140.30 & 18 & 0 & $12.0: 1$ \\
140.31 & 12 & 1 & $9.0: 1$ \\
\hline Total & 271 & 30 & \\
\hline
\end{tabular}

Only with family 140.20 is there an indication that dwarfness is determined by a single factor. For the remaining cases, complications are indicated except in two cases where dwarf genes may be lacking.

\section{Offspring of normal plants of family 140.10}

The greatest amount of data was secured from family 140.10. The average height of the normal plants of the $F_{2}$ generation in 1920 was 138.1 $\mathrm{cm}$, with extreme heights ranging from 120 to $159 \mathrm{~cm}$, although there was one plant measuring but $95 \mathrm{~cm}$ tall. This plant produced offspring only of normal height in 1921 and was evidently pure for this character. At any rate, no dwarfs were secured from 26 offspring plants. 
The dwarfs of 140.10 had an average height of $25.8 \mathrm{~cm}$, the extremes being 9 and $43 \mathrm{~cm}$. The possibility that the dwarf zygotes were less viable than the normal zygotes and thus failed to grow or failed to produce plants living until the close of the growing season, similar to the conditions found by Mryazawa (1921), is untenable. For the $F_{3}$ generation of 1921 a calculation was made of the percentage of plants coming to maturity, based upon number of seeds sown. As stated, 36 families produced no dwarfs while 42 families produced dwarfs. The percentage of dwarfs per family for the dwarf-carrying families was 18.86 percent. The families producing no dwarfs brought $63.06 \pm 1.02$ percent of the parent seed to maturity while the families producing dwarfs brought $62: 23 \pm 1.06$ percent of the parent seed to mature plants, or plants which were secured at harvest. If an appreciable number of zygotes had failed to grow at all or to grow sufficiently to be harvested, the fact should have been reflected in a difference of the above means.

Family 140.10 in 1920 produced 96 normals and 18 dwarfs. This obviously approaches a $55: 9$ ratio. If JoHANnSEN's formula for the probable error of a Mendelian ratio, as modified by BABCOCK and CLAUSEN (1918); be applied to the ratio in question the following relation results:

$\begin{array}{lcccc}\begin{array}{c}\text { Phenotype } \\ \text { Normal }\end{array} & \text { Plants } & \begin{array}{c}\text { Observed } \\ \text { ratio }\end{array} & \begin{array}{c}\text { Calculated } \\ \text { ratio }\end{array} & \begin{array}{c}\text { Probable } \\ \text { error }\end{array} \\ \text { Dwarf } & 96 & 53.9 & 55 & \pm 1.405 \\ & 18 & 10.1 & 9 & \end{array}$

The deviation is found to be less than the probable error. The two families, 140.10 and 140.17 , taken together, approximate more closely a $55: 9$ ratio than family 140.10 , but families 140.7 and 140.11 can not be brought into accord. ${ }^{2}$ Certainly the presumption would be that four $F_{1}$ plants derived by crossing similar parents would possess genotypes nearly or quite identical relative to the character of dwarfness. The data from family 140.10 are extensive, and with additional available data, the character of the genotype of the $F_{1}$ hybrid is foreshadowed.

Of the 96 normal $F_{2}$ plants produced in 1920 from 140.10, 78 were planted and 78 families resulted. Of these 78 families, 36 produced no dwarfs in the $\mathbf{F}_{3}$ generation in 1921 and were thus considered to be dwarffree. $^{3}$ The 42 families which carried dwarfs showed different kinds of segregation indicated in table 3.

\footnotetext{
2 Evidence will be presented later to show that the genotype of family 140.11 was perhaps of a nature to produce offspring at the ratio of $55: 9$ (see table 13 and accompanying text).

${ }^{3}$ It will be shown later that this conclusion was not quite true.
} 
TABLE 3

Distribution of dwarf-bearing families relative to normal-to-dwarf ratios found in the $F_{3}$ generation of family 140.10 from a Marquis-Kota cross.

\begin{tabular}{|c|c|c|c|}
\hline FAM ILY NO. 149 & NORMALS & DWARES & RATIO \\
\hline $\begin{array}{r}45 \\
50 \\
58 \\
59 \\
61 \\
63 \\
71 \\
77 \\
84 \\
93 \\
103 \\
109 \\
117\end{array}$ & $\begin{array}{l}47 \\
35 \\
48 \\
42 \\
48 \\
42 \\
54 \\
50 \\
43 \\
51 \\
21 \\
47 \\
50\end{array}$ & $\begin{array}{r}19 \\
13 \\
16 \\
17 \\
6 \\
16 \\
14 \\
20 \\
13 \\
19 \\
7 \\
12 \\
15\end{array}$ & $\begin{array}{l}2.5: 1 \\
2.7: 1 \\
3.0: 1 \\
2.5: 1 \\
3.0: 1 \\
2.6: 1 \\
3.9: 1 \\
2.5: 1 \\
3.4: 1 \\
2.7: 1 \\
3.0: 1 \\
3.9: 1 \\
3.3: 1\end{array}$ \\
\hline Total & $\begin{array}{c}578 \\
R: \text { tiogr }\end{array}$ & $\begin{array}{c}197 \\
.00: 1\end{array}$ & $2.9: 1$ \\
\hline $\begin{array}{l}51 \\
57 \\
70 \\
72 \\
87\end{array}$ & $\begin{array}{l}46 \\
56 \\
59 \\
57 \\
38\end{array}$ & $\begin{array}{r}11 \\
13 \\
12 \\
14 \\
8\end{array}$ & $\begin{array}{l}4.2: 1 \\
4.2: 1 \\
4.9: 1 \\
4.1: 1 \\
4.8: 1\end{array}$ \\
\hline Total & $\begin{array}{l}256 \\
\text { Ratio gr }\end{array}$ & $\begin{array}{c}58 \\
3: 3 \text { or }\end{array}$ & $4.4: 1$ \\
\hline $\begin{array}{c}44 \\
54 \\
55 \\
75 \\
81 \\
83 \\
89 \\
90 \\
92 \\
96 \\
9 \\
105 \\
113 \\
115 \\
116\end{array}$ & $\begin{array}{l}56 \\
49 \\
47 \\
41 \\
55 \\
38 \\
53 \\
37 \\
49 \\
53 \\
47 \\
44 \\
73 \\
66 \\
62\end{array}$ & $\begin{array}{r}8 \\
8 \\
9 \\
7 \\
8 \\
6 \\
6 \\
4 \\
9 \\
8 \\
6 \\
7 \\
8 \\
12 \\
11\end{array}$ & $\begin{array}{l}7.0: 1 \\
6.1: 1 \\
5.2: 1 \\
5.9: 1 \\
6.9: 1 \\
6.3: 1 \\
8.8: 1 \\
9.3: 1 \\
5.4: 1 \\
6.6: 1 \\
7.8: 1 \\
6.3: 1 \\
9.1: 1 \\
5.5: 1 \\
5.6: 1\end{array}$ \\
\hline Total & $\begin{array}{c}697 \\
\text { Fatio } \mathrm{gr}\end{array}$ & $\begin{array}{l}117 \\
: 9 \text { or }\end{array}$ & $6.0: 1$ \\
\hline $\begin{array}{c}4 \\
60 \\
64 \\
95 \\
99 \\
100 \\
101\end{array}$ & $\begin{array}{l}49 \\
55 \\
55 \\
58 \\
67 \\
40 \\
45\end{array}$ & $\begin{array}{l}4 \\
3 \\
4 \\
3 \\
3 \\
3 \\
4\end{array}$ & $\begin{array}{r}12.0: 1 \\
18.3: 1 \\
13.8: 1 \\
19.3: 1 \\
22.3: 1 \\
13.3: 1 \\
11.3: 1\end{array}$ \\
\hline Total & $\begin{array}{c}368 \\
\text { Ratio gr }\end{array}$ & $\begin{array}{l}24 \\
: 1\end{array}$ & $15.3: 1$ \\
\hline $\begin{array}{r}68 \\
104\end{array}$ & $\begin{array}{l}61 \\
77\end{array}$ & $\begin{array}{l}1 \\
1\end{array}$ & $\begin{array}{l}61.0: 1 \\
77.0: 1\end{array}$ \\
\hline Total & $\begin{array}{c}138 \\
\text { Ratio gr }\end{array}$ & $: 1$ & $69.0: 1$ \\
\hline
\end{tabular}


Summarizing the foregoing table it is seen that evidently there are five kinds of segregation; first, the simple $3: 1$, then $13: 3,55: 9,15: 1$ and $63: 1$. These ratios are not followed exactly but are very closely approximated. Table 4 presents a summary of table 3 .

\begin{tabular}{c|c|r|r}
\hline \multicolumn{3}{c}{ TABLE 4} \\
\hline $\begin{array}{c}\text { NuMBER } \\
\text { FAMILIES }\end{array}$ & NORMALS & DWARFS & \multicolumn{1}{|c}{ RATIO } \\
\hline 13 & 578 & 197 & $2.9: 1$ \\
5 & 256 & 58 & $13.2: 3$ \\
15 & 697 & 117 & $53.6: 9$ \\
7 & 368 & 24 & $15.3: 1$ \\
2 & 138 & 2 & $69.0: 1$ \\
\hline
\end{tabular}

The average number of individuals perfamily in the 78 families in the $F_{3}$ generation was 59 , but in a few of the families the individuals per family were less than half this number. As two of the families had only one dwarf each with the total individuals per family above 60 , it is quite possible that certain of the families which showed no dwarfs in 1921 were really not homozygous for normals but showed all normals simply because of too few individuals. As will be seen later, this was found to be true. It is possible to reduce the five ratio groups shown in tables 3 and 4 to four groups by classifying three of the families of the second group with ratio group $3: 1$, and two of the families with ratio group $55: 9$. This does not change the ratios materially and adds to the difficulty of solving the problem.

Offspring of dwarf plants of family 140.10

Although 18 dwarf plants were produced in 1920, only three of them produced seed and only one plant produced seed in any quantity. The dwarf plant, given the number 152.8 (see figure 1), measured $43 \mathrm{~cm}$, produced 105 seeds which were all planted, and in 1921, in the $F_{3}$ generation, 76 plants resulted. An even larger percentage of dwarf plants came to maturity from seeds produced by a dwarf than from seed from normal plants. The zygotes surviving during the season were 72 percent, as against 63 percent of plants surviving to maturity from seed producing only normal plants. This indicates again the absence of any lethal action upon the dwarf zygotes. This apparently greater viability perhaps may be explained by the fact that some of the smaller seeds of the dwarf plant were germinated between blotters before being planted out in the field. At any rate there is no evidence of markedly greater failure of seeds producing dwarf plants to develop to maturity, over seeds producing normal plants. Of the 76 resulting plants, 27 were phenotypic normals and 49 were Genetics 9: My 1924 
phenotypic dwarfs. One, or perhaps two, of the dwarfs were perhaps tall enough to have gone into the normal group, but a further test of them showed that they were not normal and produced but a few normal offspring.

The 76 plants of the $F_{3}$ generation resulting in 1921 from the dwarf plant 152.8 were distributed as shown in the following tabulation:

$\begin{array}{lllllllllll}\text { Class centers in } \mathrm{dm} \ldots \ldots \ldots & 2.5 & 3.5 & 4.5 & 5.5 & 6.5 & 7.5 & 8.5 & 9.5 & 10.5 & 11.5\end{array}$

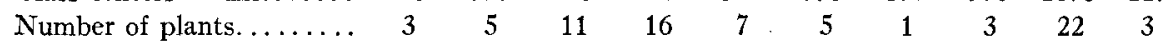

The bimodality of the foregoing distribution is very striking. In dividing the wheat plants into the two groups, normal and dwarf, the point of nine decimeters was taken. It is seen at once that this is a natural division point and no further argument is needed to sustain it. Plants taller than nine decimeters were considered to be normal and those below were considered to be dwarf. In the foregoing case, trials in 1922 showed that one of the plants, measuring $93 \mathrm{~cm}$, produced mainly dwarf offspring and had a different genotype than the other plants measuring 9 decimeters or more. On the face of the foregoing tabulation 28 normal and 48 dwarf plants resulted from an $F_{2}$ dwarf plant. Changing the position of the foregoing plant, changes this distribution to 27 and 49 . Omitting this plant from consideration for the present, there were 27 plants which were probably pure for normal height. Seed from 10 of these 27 plants, ranging in height from 100 to $110 \mathrm{~cm}$, was not planted in 1922, and the constitution of these was not known from the behavior of their offspring. However, seed of the remaining 17 normal plants was planted in 1922 and the resulting offspring were all entirely normal.

Of the 49 plants which evidently were wholly dwarf or at least heterozygous for dwarfness, only 38 were represented in the 1922 plantings. Of the 11 plants not represented, eight produced no seed whatever, one produced non-viable seeds, another plant produced four seeds, none of which came to maturity, and one number was lost. The 1922 off spring of the remaining 38 parent plants which were obviously not normal in height (excepting one plant) are shown distributed in table 5. In this table the parent height is given, number of dwarf and normal plants, and the ratio of the two.

A study of table 5 shows in nearly all cases an abrupt falling off of variates immediately below the 95 -cm class center. This corresponds closely to the grouping of plants in the parent family. In only one case, family 157.19 , is there a continuous distribution from the very obviously dwarf height of $35 \mathrm{~cm}$ up to the normal height of about one meter. In this case dwarf plants greatly outnumber normals. With family 157.50 it is 
TABLE 5

Distribution of offspring of the $F_{4}$ generation from the obviously non-normal plants shown in the foregoing tabulation.

\begin{tabular}{|c|c|c|c|c|c|c|c|c|c|c|c|c|c|c|c|c|}
\hline \multirow{2}{*}{ NUMBER } & \multirow{2}{*}{$\begin{array}{c}\text { PARFN- } \\
\text { IAL } \\
\text { HEIGHT }\end{array}$} & \multirow{2}{*}{ DWARF } & \multirow{2}{*}{ NORMAL } & \multirow{2}{*}{ RATIO } & \multicolumn{12}{|c|}{ CLASS CENTERS IN CENTIMETERS } \\
\hline & & & & & 15 & 25 & 35 & 45 & 55 & 65 & 75 & 85 & 95 & 105 & 115 & 125 \\
\hline 157. & & & & & & & & & & & & & & & & \\
\hline 18 & 93 & 87 & 3 & $29.0: 1$ & & 4 & 12 & 27 & 24 & 10 & 9 & 1 & 3 & & & \\
\hline 19 & 89 & 92 & 2 & $46.0: 1$ & 1 & 12 & 31 & 20 & 16 & 4 & 5 & 3 & 1 & 1 & & \\
\hline 20 & 72 & 43 & 23 & $1.0: 9$ & & 13 & 16 & 8 & 0 & 6 & 0 & 0 & 2 & 6 & 11 & 4 \\
\hline 21 & 71 & 56 & 4 & $14.0: 1$ & 4 & 16 & 19 & 11 & 3 & 2 & 1 & 0 & 0 & 4 & & \\
\hline 22 & 72 & 64 & 4 & $16.0: 1$ & 2 & 22 & 18 & 14 & 7 & 1 & 0 & 0 & 1 & 3 & & \\
\hline 23 & 72 & 89 & 1 & $89.0: 1$ & 1 & 31 & 34 & 17 & 6 & 0 & 0 & 0 & $\mathbf{0}$ & 1 & & \\
\hline 24 & 71 & 39 & 0 & $1.0: 0$ & & 9 & 8 & 8 & 13 & 1 & & & & & & \\
\hline 25 & 68 & 34 & 1 & $34.0: 1$ & 1 & 13 & 9 & 6 & 4 & 0 & 0 & 1 & 0 & 0 & 1 & \\
\hline 26 & 63 & 36 & 9 & $4.0: 1$ & 3 & 19 & 7 & 5 & 1 & 1 & 0 & 0 & 2 & 7 & & \\
\hline 27 & 54 & 14 & 3 & $4.7: 1$ & & 5 & 2 & 5 & 2 & 0 & 0 & 0 & 0 & 1 & 2 & \\
\hline 28 & 60 & 27 & 11 & $2.5: 1$ & 1 & 11 & 10 & 4 & 0 & 1 & 0 & 0 & 3 & 5 & 3 & \\
\hline 29 & 63 & 30 & 0 & $1.0: 0$ & & 11 & 7 & 10 & 2 & & & & & & & \\
\hline 30 & 65 & 44 & 16 & $2.75: 1$ & 2 & 15 & 20 & 4 & 1 & 1 & 1 & 0 & 6 & 8 & 2 & \\
\hline 31 & 58 & Lost & in 1921 & -22 & & & & & & & & & & & & \\
\hline 32 & 60 & 27 & 9 & $3.0: 1$ & 3 & 6 & 10 & 8 & 0 & 0 & 0 & 0 & 2 & 5 & 2 & \\
\hline 33 & 58 & 15 & 9 & $1.7: 1$ & 3 & 4 & 7 & 1 & 0 & 0 & 0 & 0 & 2 & 7 & & \\
\hline 34 & 56 & 12 & 5 & $2.4: 1$ & 2 & 4 & 4 & 1 & 1 & 0 & 0 & 0 & 1 & 3 & 1 & \\
\hline 35 & 57 & 51 & 12 & $4.2: 1$ & 3 & 28 & 14 & 6 & 0 & 0 & 0 & 0 & 3 & 7 & 2 & \\
\hline 36 & 48 & 29 & 1 & $29.0: 1$ & 1 & 9 & 10 & 5 & 4 & 0 & 0 & 0 & 1 & & & \\
\hline 37 & 59 & 24 & 7 & $3.4: 1$ & 1 & 11 & 7 & 3 & 1 & 0 & 1 & 0 & 1 & 3 & 3 & \\
\hline 38 & 56 & 19 & 13 & $1.5: 1$ & 2 & 13 & 3 & 1 & 0 & 0 & 0 & 0 & 4 & 6 & 3 & \\
\hline 39 & 61 & 17 & 8 & $2.1: 1$ & & 9 & 3 & 5 & 0 & 0 & 0 & 0 & $\mathbf{0}$ & 5 & 3 & \\
\hline 40 & \begin{tabular}{l|l} 
|) 54 \\
|
\end{tabular} & 13 & 2 & $6.5: 1$ & 2 & 5 & 3 & 3 & 0 & 0 & 0 & 0 & $\mathbf{0}$ & 2 & & \\
\hline 41 & 50 & 6 & 8 & $0.75: 1$ & & 6 & 0 & 0 & 0 & 0 & 0 & 0 & 1 & 1 & 4 & 2 \\
\hline 42 & 57 & 25 & 1 & $25.0: 1$ & 3 & 8 & 8 & 6 & 0 & 0 & 0 & 0 & 0 & 0 & 1 & \\
\hline 43 & 43 & 0 & $\mathbf{0}$ & & & & & & & & & & & & & \\
\hline 44 & 49 & 30 & 10 & $3.0: 1$ & 3 & 10 & 16 & 0 & 0 & 1 & 0 & $\mathbf{0}$ & 4 & 4 & 2 & \\
\hline 45 & 58 & 24 & 0 & $1.0: 0$ & & 3 & 11 & 6 & 4 & & & & & & & \\
\hline 46 & 52 & 8 & 2 & $4.0: 1$ & 1 & 3 & 1 & 2 & 0 & 1 & 0 & 0 & 0 & 2 & & \\
\hline 47 & 57 & 22 & 0 & $1.0: 0$ & & & 8 & 8 & 5 & 1 & & & & & & \\
\hline 48 & 58 & 2 & 1 & $2.0: 1$ & 1 & 0 & 1 & 0 & 0 & 0 & 0 & 0 & 0 & 1 & & \\
\hline 49 & 48 & 8 & 4 & $2.0: 1$ & & & 3 & 2 & 2 & 1 & 0 & $\mathbf{0}$ & 0 & 2 & 2 & \\
\hline 50 & 53 & 22 & 6 & $3.7: 1$ & 3 & 7 & 8 & 1 & 0 & 0 & 1 & 2 & 5 & 1 & & \\
\hline 51 & 46 & 6 & 4 & $1.5: 1$ & & 2 & 2 & 0 & 1 & 1 & 0 & 0 & 1 & 2 & 1 & \\
\hline 52 & 55 & 3 & 1 & $3.0: 1$ & & & 2 & 1 & 0 & 0 & 0 & $\mathbf{0}$ & 0 & 1 & & \\
\hline 53 & 47 & 3 & 3 & $1.0: 1$ & & 1 & 2 & 0 & 0 & 0 & 0 & 0 & 0 & 1 & 1 & 1 \\
\hline 54 & 46 & 20 & 6 & $3.3: 1$ & 2 & 8 & 8 & 2 & 0 & 0 & 0 & 0 & 3 & 3 & & \\
\hline 55 & 47 & 27 & 9 & $3.0: 1$ & 1 & 3 & 11 & 8 & 1 & 2 & 0 & 1 & 2 & 5 & 2 & \\
\hline 56 & 38 & 12 & 3 & $4.0: 1$ & & 4 & 7 & 1 & 0 & 0 & 0 & 0 & 1 & 2 & & \\
\hline $57 \mid$ & 38 & 5 & 5 & $1.0: 1$ & 2 & 2 & 1 & 0 & 0 & 0 & 0 & 0 & 0 & 3 & 2 & \\
\hline
\end{tabular}

possible the classification of dwarfs as given is not correct and that the three plants at $75 \mathrm{~cm}$ and $85 \mathrm{~cm}$ are pure for normal height, although Genetics 9: My 1924 
this is unlikely. In a few cases there are plants apparently intermediate between dwarfs and normals, the plant centering at $85 \mathrm{~cm}$, family 157.25, being a striking example. Four of the families (numbers 24, 29, 45 and 47) carry all dwarfs, no plants of normal height being present. It is possible that in one or more of these families, normal plants are absent because of too small numbers but this would hardly be true of all the four families.

TABLE 6

Distributions of table 5 condensed and rearranged to show approach to Mendelian ratios.

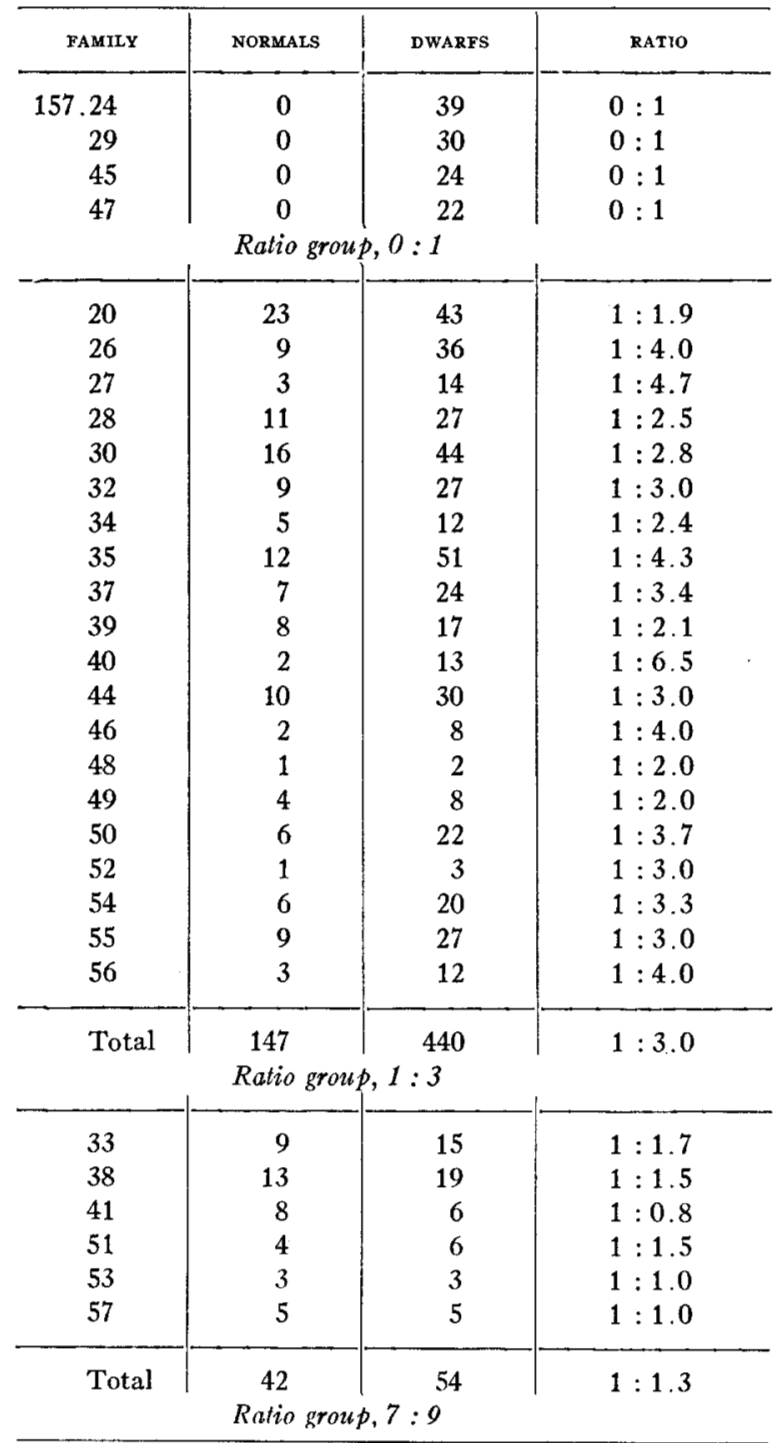


TABLE 6 (continued)

\begin{tabular}{c|c|c|c}
\hline FAMIIY & NORMALS & DWARY & RAT.O \\
\hline 21 & 4 & 56 & $1: 14.0$ \\
22 & 4 & 64 & $1: 16.0$ \\
\hline Total & 8 & 120 & $1: 15.0$ \\
& Ratio grou $p, 1: 15$ & \\
\hline 18 & 3 & 87 & $1: 29.0$ \\
25 & 1 & 34 & $1: 34.0$ \\
35 & 1 & 29 & $1: 29.0$ \\
42 & 1 & 25 & $1: 25.0$ \\
\hline Total & 6 & 175 & $1: 29.2$ \\
& Ratio groutp, (?) & \\
\hline 19 & 2 & 92 & $1: 46.0$ \\
23 & 1 & 89 & $1: 89.0$ \\
\hline Total & 3 & 181 & $1: 60.3$ \\
& Ratio groutp, $1: 63$ & \\
\hline
\end{tabular}

It is evident from table 5 that a diversity of ratios is present in regard to dwarf and normal plants. How closely the dwarf and normal plants approximate certain well-established ratios is shown in table 6 .

One notes that the ratios $1: 3,7: 9$ and $1: 15$ are fulfilled exactly, only one additional dwarf being needed in the case of the $1: 3$ ratio. Families 18, 25, 36 and 42 present a ratio quite out of the ordinary and discussion of this will be withheld for the present. The ratio of $1: 60.3$ from families 19 and 23, is to be interpreted as a $1: 63$ ratio; the approximation is satisfactorily close. Reference to table 5 shows that in family 23 there is no possible confusion between the normal plant and the dwarfs. The normal plant was over one meter and none of the dwarfs was as tall as sixty centimeters.

The dwarf plants in 1921, which produced no seed, were among the shortest. Only two plants below $40 \mathrm{~cm}$ produced seed. However, one cannot draw the conclusion that the shorter plants were always the more nearly homozygous for dwarfness. Family 57 of 1922, the parent plant of which was but $38 \mathrm{~cm}$ tall, produced 50 percent normals and family 56 with the same height of parent plant produced 25 percent normals. One of the families producing all dwarfs, family 24 , came from a parent plant $71 \mathrm{~cm}$ tall. 


\section{Two oiher dwarf families}

In 1919 , as stated previously, three dwarf plants of cross 140.10 produced seed. The foregoing discussion has been limited to but one of these plants, having a height of $43 \mathrm{~cm}$. In 1921 there were secured from the two other dwarf plants five dwarfs ranging in height from 24 to $48 \mathrm{~cm}$, the shortest plant producing no seed. A total of 48 seeds from the four remaining plants was planted, 23 plants coming to maturity in $1922 .{ }^{4}$ The distribution of the 23 offspring plants is shown in table 7 .

TABLE 7

Distribution of normal and dwarf plants in families derived from dwarf plants.

\begin{tabular}{|c|c|c|c|c|c|c|c|c|}
\hline \multirow{2}{*}{ NUMBEER } & \multirow{2}{*}{$\begin{array}{l}\text { PARENTAL } \\
\text { HEIGHT }\end{array}$} & \multirow{2}{*}{ NORMAI } & \multirow{2}{*}{ DWARF } & \multirow{2}{*}{ RATIO } & \multicolumn{4}{|c|}{ CLASS CENTERS IN CM } \\
\hline & & & & & 15 & 25 & 35 & 105 \\
\hline 157.77 & 36 & 1 & 6 & $1: 6.0$ & 2 & 4 & 0 & 1 \\
\hline 78 & 48 & 2 & 5 & $1: 2.5$ & 0 & 3 & 1 & 2 \\
\hline 79 & 39 & 0 & 5 & $1: 0.0$ & 1 & 3 & 1 & 0 \\
\hline 80 & 34 & 2 & 2 & $1: 1.0$ & 0 & 2 & 0 & 2 \\
\hline
\end{tabular}

The foregoing numbers are too meagre to warrant drawing any conclusions, but perhaps a $1: 3$ ratio is indicated, while one family may be pure for dwarf character. Family 157.80 might reveal a $7: 9$ ratio if more plants were available. This ratio might be looked for in this connection as will appear later on in the discussion.

Dwarf and normal plants secured in 1922 from phenotypically normal parents

In 1922 six families were planted of series 149 , numbered $64,65,74,77$, 78 and 98 . Families 65,74 , and 78 are not shown in table 3 as there were no dwarfs in these three families in 1921. In family 64 four dwarfs were found in a total of 59 plants, the ratio being $13.8: 1$ which brought the family into the $15: 1$ ratio group. In 1922 the parent family 64 of 1921 produced 55 families, no dwarfs being present in 28 of these families. For the remaining 27 families normal and dwarf plants were produced as shown in table 8.

The plant 149.64 of table 3 producing the foregoing families appeared to be simply dihybrid in character with two dominant factors responsible for normal height, for out of a total of 59 offspring there were four dwarf plants. In the succeeding generation, shown in table 8 , it is evident that conditions in the genotype governing dwarfness are considerably more

${ }^{4}$ In this case the number of plants harvested was only 48 percent of the number of seeds sown. Seeds from dwarf plants are nearly always shriveled and deficient in endosperm, which is usually responsible for less successful growth. 
TABLE 8

Distribution, relative to normal-dwarf ratios, of dwarf-bearing families found in the $F_{4}$ generation of a family 149.64 derived from a Marquis-Kota cross.

\begin{tabular}{|c|c|c|c|}
\hline FAMILY & NORMALS & DWARFS & RATIO \\
\hline \multirow[t]{2}{*}{156.47} & 80 & 25 & $3.2: 1$ \\
\hline & \multicolumn{3}{|c|}{ Ratio group, $3: 1$} \\
\hline 156. 3 & 59 & 13 & $4.5: 1$ \\
\hline 9 & 58 & 14 & $4.1: 1$ \\
\hline 17 & 53 & 14 & $3.8: 1$ \\
\hline 32 & 60 & 13 & $4.6: 1$ \\
\hline 44 & 71 & 16 & $4.4: 1$ \\
\hline 48 & 95 & 23 & $4.1: 1$ \\
\hline 49 & 96 & 21 & $4.6: 1$ \\
\hline \multirow[t]{2}{*}{ Total } & 492 & 114 & $4.3: 1$ \\
\hline & \multicolumn{3}{|c|}{ Ratio group, $13: 3$} \\
\hline 156. 5 & 79 & 9 & $8.8: 1$ \\
\hline 6 & 52 & 8 & $6.5: 1$ \\
\hline 7 & 38 & 7 & $5.4: 1$ \\
\hline 8 & 57 & 11 & $5.2: 1$ \\
\hline 10 & 65 & 9 & $7.2: 1$ \\
\hline 22 & 59 & 6 & $9.8: 1$ \\
\hline 24 & 48 & 6 & $8.0: 1$ \\
\hline 26 & 89 & 10 & $8.9: 1$ \\
\hline 37 & 71 & 14 & $5.1: 1$ \\
\hline 38 & 68 & 10 & $6.6: 1$ \\
\hline 42 & 99 & 16 & $6.2: 1$ \\
\hline 46 & 98 & 19 & $5.2: 1$ \\
\hline 53 & 86 & 14 & $6.1: 1$ \\
\hline 55 & 65 & 8 & $8.1: 1$ \\
\hline \multirow[t]{2}{*}{ Total } & 974 & 147 & $6.6: 1$ \\
\hline & \multicolumn{3}{|c|}{ Ratio group, $55: 9$} \\
\hline 156. 4 & 55 & 5 & $11.0: 1$ \\
\hline 31 & 50 & 5 & $10.0: 1$ \\
\hline 52 & 62 & 4 & $15.5: 1$ \\
\hline \multirow[t]{2}{*}{ Total } & 167 & 14 & $11.9: 1$ \\
\hline & \multicolumn{3}{|c|}{ Ratio group, $15: 1$} \\
\hline 156.11 & 94 & 2 & $47.0: 1$ \\
\hline 45 & 103 & 1 & $103.0: 1$ \\
\hline \multirow[t]{2}{*}{ Total } & 197 & 3 & $65.3: 1$ \\
\hline & \multicolumn{3}{|c|}{ Ratio group, $63: 1$} \\
\hline
\end{tabular}


complicated. The following ratios of normals to dwarfs are apparently to be observed in the families resulting from family 149.64 , namely, $3: 1$, $13: 3,55: 9,15: 1$ and $63: 1$. Probable errors for these ratios were determined and are shown in table 9.

TABLE 9

Closeness of fit of the observed ratios of table 8 to the calculated ratios.

\begin{tabular}{c|c|c|c}
\hline ONEERVED & CAICULATED & THEORETICAT & ERROR \\
\hline 80 & $\begin{array}{r}3.045 \\
.952\end{array}$ & 3 & \pm 0.114 \\
25 & 1 & \\
\hline 105 & 4.000 & 4 & \\
\hline 492 & 12.990 & 13 & \pm 0.171 \\
114 & 3.010 & 3 & \\
\hline 606 & 16.000 & 16 & \\
\hline 974 & 55.607 & 55 & \pm 0.448 \\
147 & 8.393 & 9 & \\
\hline 1121 & 64.000 & 64 & \\
\hline 154 & 14.754 & 15 & \pm 0.202 \\
13 & 1.246 & 1 & \\
\hline 167 & 16.000 & 16 & \\
\hline 197 & 63.040 & 63 & \pm 0.379 \\
\hline 3 & .960 & 1 & \\
\hline 200 & 64.000 & 64 & \\
\hline & & & \\
\hline
\end{tabular}

In any arrangement like that shown in table 8 some of the more pronounced deviates may be found to have been wrongly placed when another generation is grown. The theoretical and observed ratios are observed to fit very closely. In no case does the observed ratio deviate from the calculated as much as 50 percent more than the probable error. Certain individual family ratios naturally show greater deviation than the mean of several combined families, but most of the individual families are satisfactorily close to their ascribed ratios. The argument might be advanced that from a miscellaneous lot of families, such as shown in table 8 , it would be possible to group the families in such a manner as to show almost any series of ratios. The fact of the matter is that the grouping shown in table 8 is the only satisfactory one that can be devised, using ordinary 
Mendelian ratios. When the data of table 8 are compared with those of table 3 , a striking similarity is observed in that the same ratios are found in both cases, although not in the same proportions. Similarity too close for an accidental occurrence is evident between the genotypes of the grandparent producing the families derived from family 149.64 , of table 8 , and the $F_{1}$ hybrid plant of the original cross.

Family 149.65 produced no dwarfs in 1921 in a total of 61 plants. In 1922, 60 families were grown from the one family of 1921. There resulted 58 families free from dwarfs while two families showed dwarfs as follows:

$\begin{array}{rccc}\text { Family } & \text { Normals } & \text { Dwarfs } & \text { Ratio } \\ 156 . & & & \\ 71 & 82 & 1 & 82: 1 \\ 114 & 58 & 1 & 58: 1 \\ & -140 & - & -70: 1 \\ & \text { Ratio group, } 63: 1 & \end{array}$

A very simple explanation of the segregation shown in the offspring of family 149.65 seems to be that the plant producing in 1921 the family carrying no dwarfs was really heterozygous for three factors, each responsible for normal height. But if this had been the case, out of 64 plants taken at random from the 1921 family ( 60 were actually used) eight would show offspring ratios of $63: 1,12$ would show ratios of $15: 1$, and 6 ratios of $3: 1$. Nothing of the kind occurred, for only two families had a ratio of $63: 1$, while the remainder of the families produced no dwarfs.

Family 149.74 had 57 individuals in 1921, none of which was dwarf. Twenty-five families were grown in 1922 from the parent family and again no dwarfs were produced.

Of family $149.77,70$ plants were grown in 1921 and 20 of these were dwarfs. The ratio of normals to dwarfs was thus $2.5: 1$. In 1922 only 20 families were grown, using normal parent plants taken at random. Of these 20 parent plants, six produced normal offspring plants only. The 14 families carrying both normal and dwarf plants had the offspring in 1922 shown in table 10.

The ratio groups of the offspring of family 149.77 shown in table 10 are the same as those of table 8 except that the $13: 3$ group does not appear. While the families entering into the ratio group $55: 9$ fit less closely to the expected than in some of the other corresponding cases, the fit is acceptable for the two families as a unit, as the deviation with its probable error is $1.147 \pm 1.213$. It is not desired to enter into a full discussion of these results until later, but attention is called to the four classes Genetics 9: My 1924 
of families listed in table 10 . The 20 parent plants, normal in height, were taken from a family ratioed $2.5: 1$ of normal to dwarf plants. If the segregation in the parent family of normals and dwarfs was brought about by a single factor, as is apparently the case, it becomes difficult to explain the $55: 9,15: 1$, and $63: 1$ resulting ratios.

\section{TABLE 10}

Distribution, relative to dwarf ratios, of dwarf-bearing families found in the $F_{4}$ generation of family 149.77 derived from a Marquis-Kota cross.

\begin{tabular}{|c|c|c|c|}
\hline FAMILY & NORMALS & DWARFS & RATIO \\
\hline \multicolumn{4}{|l|}{156.} \\
\hline 142 & 24 & 8 & $3.0: 1$ \\
\hline 149 & 50 & 15 & $3.3: 1$ \\
\hline 152 & 69 & 23 & $3.0: 1$ \\
\hline 155 & 36 & 11 & $3.3: 1$ \\
\hline 156 & 31 & 9 & $3.4: 1$ \\
\hline 157 & 38 & 10 & $3.8: 1$ \\
\hline 160 & 45 & 15 & $3.0: 1$ \\
\hline 161 & 17 & 8 & $2.7: 1$ \\
\hline \multirow[t]{2}{*}{ Total } & 310 & 99 & $3.1: 1$ \\
\hline & \multicolumn{2}{|c|}{ Ratio group, $3: 1$} & \\
\hline 148 & 72 & 8 & $9.0: 1$ \\
\hline 154 & 71 & 12 & $5.9: 1$ \\
\hline \multirow[t]{2}{*}{ Total } & 143 & 20 & $7.2: 1$ \\
\hline & \multicolumn{2}{|c|}{ Ratio group, $55: 9$ (?) } & \\
\hline 147 & 49 & 3 & $16.3: 1$ \\
\hline 150 & 79 & 5 & $15.8: 1$ \\
\hline \multirow[t]{2}{*}{ Total } & 128 & 8 & $16.0: 1$ \\
\hline & \multicolumn{2}{|c|}{ Ratio group $15: 1$} & \\
\hline 146 & 74 & 1 & $74.0: 1$ \\
\hline 153 & 86 & 2 & $43.0: 1$ \\
\hline \multirow[t]{2}{*}{ Total } & 160 & 3 & $53.3: 1$ \\
\hline & \multicolumn{2}{|c|}{ Ratio group $63: 1$} & \\
\hline
\end{tabular}

\section{Family 149.78}

Family 149.78 in 1921 carried no dwarfs; all plants were of normal stature. In 1922 seeds of 39 plants were planted and of the 39 families, 32 carried normals only and seven families carried both normals and dwarfs, as shown in table 11. 
Families 149.65 and 78 are of course omitted from table 3 as they produced no dwarfs, but with this added knowledge of their genotype evidently they should have been included, presumably in the group ratio $63: 1$, making at least four families segregating $63: 1$.

Family 149.78 and its offspring families show a condition similar to that of family 149.65. Here there is strong evidence, apparently, that three (triplicate) factors are responsible for the normal character, but there is no obvious explanation why nearly all the families carrying dwarfs should

\section{TABLE 11}

Distribution, relative to dwarf ratios, of dwatf-bearing families found in the $F_{4}$ generation of a family 149.78 derived from a Marquis-Kota cross.

\begin{tabular}{|c|c|c|c|}
\hline FAMILY & NoRMaLS & DWARFS & RATIO \\
\hline 156. & $\begin{array}{l}95 \\
\text { Ratio }\end{array}$ & $\begin{array}{c}5 \\
15: 1\end{array}$ & $19.0: 1$ \\
\hline $\begin{array}{l}171 \\
173 \\
180 \\
187 \\
193 \\
199\end{array}$ & $\begin{array}{r}73 \\
97 \\
96 \\
106 \\
92 \\
117\end{array}$ & $\begin{array}{l}1 \\
2 \\
1 \\
2 \\
2 \\
1\end{array}$ & $\begin{array}{r}73.0: 1 \\
48.5: 1 \\
96.0: 1 \\
53.0: 1 \\
46.0: 1 \\
117.0: 1\end{array}$ \\
\hline Total & $\begin{array}{l}581 \\
\text { Ratio }\end{array}$ & $\begin{array}{c}9 \\
63: 1\end{array}$ & $64.5: 1$ \\
\hline
\end{tabular}

be of the ratio $63: 1$. On the basis of chance eight families out of 64 would throw this percentage of dwarfs and six families out of 39 is not greatly at variance. But at the same time there should be 12 families out of 64 producing normals to dwarfs in the $15: 1$ ratio and six families in the $3: 1$ ratio.

\section{Family 149.98}

Family 149.98 in 1921 contained 47 normal plants and 6 dwarfs; thus, in table 1 it is placed in the ratio group $55: 9$. In 192215 families were grown from 15 normal plants, obviously taken at random with regard to dwarfness. Of these $\mathbf{1 5}$ families seven were free of dwarfs and eight families contained dwarfs as shown in table 12 .

The fit in both of these groups is very close. In the first, less than two normal plants need to be added per family to make the ratio exact and the fit in the second group is still closer. Ratios of $13: 3$ and $55: 9$ are not uncommon in Mendelian heredity, and their presence here adds much Grantics 9: My 1924 
weight to a certain part of our general argument. More detailed remarks upon the behavior of these families will be left until the general discussion.

\section{Plant 140.11}

In the first part of the discussion of original work, mention was made of a plant, 140.11, which produced 53 normals to 15 dwarfs or at a ratio of $3.5: 1$. The later data secured from the offspring of this plant were less ample than those secured from plant 140.10 , but are of decided interest so far as they are available.

\section{TABLE 12}

Distribution, relative to normal-dwarf ratios, of dwarf-bearing families found in the $F_{4}$ generation

\begin{tabular}{c|c|c|c}
\multicolumn{2}{c}{ of family 149.98 derived from a Marquis-Kota cross. } \\
\hline FAMILY & NormaIs & Dwars & Ratio \\
\hline 156. & & & \\
-207 & 84 & 17 & $4.9: 1$ \\
209 & 70 & 16 & $4.4: 1$ \\
210 & 60 & 14 & $4.3: 1$ \\
214 & 83 & 22 & $3.8: 1$ \\
215 & 84 & 21 & $4.0: 1$ \\
\hline Total & 381 & 90 & $4.2: 1$ \\
& Ratio group, $13: 3$ & \\
\hline 202 & 28 & 3 & $9.3: 1$ \\
208 & 84 & 14 & $6.0: 1$ \\
212 & 88 & 16 & $5.5: 1$ \\
\hline Total & 200 & 33 & $6.1: 1$ \\
\hline
\end{tabular}

From the 53 normal plants, 52 were used to produce families for the $\mathbf{F}_{3}$ generation grown in 1921. Out of the 52 resulting families 23 produced no dwarfs, and 29 families carried dwarfs. This number is compared with families 149.42-119 secured from plant 140.10 , in the following tabulation:

Families $.149 .42-119$

Carrying only normals . . . . . . . . . . . . . 34

Carrying normals and dwarfs. . . . . . . . . 44

Total. . . . . . . . . .

\begin{tabular}{cc}
\multicolumn{2}{c}{$149.120-172$} \\
Observed & Calcuated \\
23 & 34.5 \\
29 & 43.5 \\
- & - \\
52 & 78.0
\end{tabular}

The ratio of families carrying only normal plants to those carrying both normals and dwarfs is seen to be practically identical in the two cases. 
The 29 families carrying both normals and dwarfs are shown in table 13.

TABLE 13

Distribution of dwarf-bearing families, relative to normal-dwarf ratios, found in the $F_{3}$ generation of plant 140.11 from a Marquis-Kota cross.

\begin{tabular}{|c|c|c|c|}
\hline FAMILY & NORMAIS & DWARFS & RATIO \\
\hline $\begin{array}{r}149 . \\
128 \\
139 \\
141 \\
156\end{array}$ & $\begin{array}{l}52 \\
56 \\
51 \\
56\end{array}$ & $\begin{array}{l}23 \\
18 \\
15 \\
15\end{array}$ & $\begin{array}{l}2.3: 1 \\
3.1: 1 \\
3.4: 1 \\
3.7: 1\end{array}$ \\
\hline Total & $\begin{array}{l}215 \\
\text { Ralio }\end{array}$ & $\begin{array}{c}71 \\
3: 1\end{array}$ & $3.0: 1$ \\
\hline $\begin{array}{l}129 \\
131 \\
136 \\
155 \\
161\end{array}$ & $\begin{array}{l}28 \\
45 \\
37 \\
50 \\
57\end{array}$ & $\begin{array}{r}7 \\
11 \\
9 \\
12 \\
12\end{array}$ & $\begin{array}{l}4.0: 1 \\
4.1: 1 \\
4.1: 1 \\
4.2: 1 \\
4.8: 1\end{array}$ \\
\hline Total & $\begin{array}{c}217 \\
\text { Ratio }\end{array}$ & $\begin{array}{c}51 \\
13: 3\end{array}$ & $4.3: 1$ \\
\hline $\begin{array}{l}123 \\
133 \\
138 \\
142 \\
144 \\
158 \\
159 \\
163 \\
167 \\
171\end{array}$ & $\begin{array}{l}60 \\
48 \\
60 \\
54 \\
50 \\
56 \\
60 \\
47 \\
24 \\
67\end{array}$ & $\begin{array}{r}8 \\
8 \\
10 \\
9 \\
6 \\
7 \\
7 \\
6 \\
3 \\
13\end{array}$ & $\begin{array}{l}7.5: 1 \\
6.0: 1 \\
6.0: 1 \\
6.0: 1 \\
8.3: 1 \\
8.0: 1 \\
8.6: 1 \\
7.8: 1 \\
8.0: 1 \\
5.2: 1\end{array}$ \\
\hline Total & $\begin{array}{l}526 \\
\text { Ratio }\end{array}$ & $\begin{array}{c}77 \\
55: 9\end{array}$ & $6.8: 1$ \\
\hline $\begin{array}{l}122 \\
126 \\
132 \\
135 \\
145 \\
147 \\
153 \\
162 \\
170 \\
172\end{array}$ & $\begin{array}{l}51 \\
59 \\
66 \\
58 \\
64 \\
60 \\
46 \\
68 \\
48 \\
61\end{array}$ & $\begin{array}{l}5 \\
5 \\
4 \\
5 \\
3 \\
4 \\
4 \\
5 \\
3 \\
6\end{array}$ & $\begin{array}{l}10.2: 1 \\
11.8: 1 \\
16.5: 1 \\
11.6: 1 \\
21.3: 1 \\
15.0: 1 \\
11.5: 1 \\
13.6: 1 \\
16.0: 1 \\
10.2: 1\end{array}$ \\
\hline Total & $\begin{array}{l}581 \\
\text { Ratio }\end{array}$ & $\begin{array}{l}44 \\
15: 1\end{array}$ & $13.2: 1$ \\
\hline
\end{tabular}


With the 29 families four ratio groups are in evidence, namely, $3: 1$, $13: 3,55: 9$ and $15: 1$. These correspond to the ratio groups shown in table 3 , except that here ratio group $63: 1$ is not represented. The closeness of fit of the different families to their ascribed ratios of table 13 is not quite so good as is found in table 3, although they are very good in both cases. The closeness of fit in the ratio groups of $3: 1$ and $13: 3$ is practically exact, but for the two other groups it is less exact than for the corresponding groups of table 3 . Even in these two groups the probable errors calculated for the ratios in the two ratio groups are of the same order of magnitude as the deviations from the observed in comparison with the theoretical ratios. One is entirely justified in dividing up the families into the four ratio groups as indicated. The deviations which are present are not greater than are commonly found in work of this kind.

When a comparison is made in the two tables, relative to the proportionate number of families entering into the two ratio groups, the results are not so satisfactory, but even here analogous comparisons can be made. If one regards either group of families as the basis toward which to work, it is impossible to rearrange the families of the other table in different ratio groups so that the closeness of fit for each ratio group will be improved. If a similarity of distribution of families among the groups in the two tables is to be made uniform, then the character of the ratio groups themselves will be greatly disturbed.

It will be remembered that a fourth generation secured from planting certain of the families of table 3 developed the fact that the ratio group $63: 1$ was represented in two cases in additional families which only came to light by growing another generation. If as large a number of families had been represented in table 13 as in table 3, or if another generation of some of the families apparently carrying all normals had been grown, a more equable chance would have been given for members of the ratio group $63: 1$ to make their appearance.

Without anticipating a discussion of the results as a whole, it is possible to point out that the ratio group $15: 1$ of table 13 is not to be looked for in connection with groups $13: 3$ and $55: 9$. In short, the data from family 140.11 strongly corroborate those from family 140.10 , with due respect to certain discrepancies in class groupings, presenting the same sort of a problem for solution.

\section{Plant 140.17}

Another plant of the Marquis-Kota cross, number 140.17, produced 60 normals and nine dwarfs in 1920. This is in the ratio of $6.7: 1$ and 
suggests a $55: 9$ ratio. In 1921 the seed of 52 normal plants out of the 60 was planted. From this lot of 52 plants, 38 families resulted carrying normal plants only, while 14 families were found to carry both normals and dwarfs. This is an entirely different condition from that obtained with the offspring of the two families 140.10 and 140.11 . With only 14 dwarfcarrying families, the numbers are too small to place satisfactorily in different group ratios, but even here it is evident that different classes are in evidence. Without attempting to make a definite grouping, the dwarf-carrying families are shown in table 14, arranged in the order of ratio size.

Table 14

\begin{tabular}{|c|c|c|c|}
\hline FAMILY & NORMAIS & DWARFS & RATIO \\
\hline 149. & & & \\
\hline 211 & 55 & 12 & $4.6: 1$ \\
\hline 182 & 50 & 10 & $5.0: 1$ \\
\hline 213 & 54 & 8 & $6.8: 1$ \\
\hline 207 & 64 & 9 & $7.1: 1$ \\
\hline 180 & 59 & 8 & $7.4: 1$ \\
\hline 192 & 73 & 8 & $9.1: 1$ \\
\hline 185 & 55 & 6 & $9.2: 1$ \\
\hline 216 & 61 & 6 & $10.2: 1$ \\
\hline 193 & 71 & 6 & $11.8: 1$ \\
\hline 173 & 48 & 4 & $12.0: 1$ \\
\hline 219 & 62 & 5 & $12.4: 1$ \\
\hline 177 & 33 & 2 & $16.5: 1$ \\
\hline 194 & 63 & 3 & $21.0: 1$ \\
\hline 186 & 66 & 3 & $22.0: 1$ \\
\hline
\end{tabular}

Evidently seven families of this table belong to the ratio group $15: 1$, and possibly two others, 149.185 and 149.192 .

\section{Results from Red Fife $\times$ Kola crosses}

Two families, 140.15 and 140.20 , from a cross, Red Fife $\times$ Kota, carried normals and dwarfs in 1920 at the rate of 19 normals to 2 dwarfs and 11 normals to 4 dwarfs, respectively, as shown in table 2 .

For our purpose these two families may be considered together. In 1921 a total of 30 families were grown from the two parent families numbered 140.15 and 140.20 . Out of the 30 families, eight produced both normal and dwarf plants, while the remaining families produced only normal plants. The ratios obtaining in the eight families carrying both normals and dwarfs are shown in table 15 . 
While the families carrying dwarfs are too few to be classified, they have a value in indicating a diversity of ratios.

This fact also is indicated in the offspring of a cross, 140.1, between the varieties Kota and Red Bobs, made in 1918. The variety Red Bobs, selected in Canada by Doctor SeAger WheEler, resulted from a field cross between the Australian variety Bobs and some other variety.

Table 15

\begin{tabular}{c|c|c|c}
\hline \multicolumn{1}{c|}{ FAMILX } & NORMALS & DWARFS & RATIO \\
\hline 149. & & & \\
233 & 43 & 9 & $4.8: 1$ \\
250 & 39 & 7 & $7.0: 1$ \\
238 & 43 & 6 & $7.2: 1$ \\
247 & 55 & 7 & $7.9: 1$ \\
249 & 44 & 5 & $8.8: 1$ \\
240 & 42 & 4 & $10.5: 1$ \\
232 & 55 & 5 & $11.0: 1$ \\
251 & 37 & 3 & $12.3: 1$ \\
\hline
\end{tabular}

In 192054 plants of the $F_{2}$ generation were produced from the $F_{1}$ plant. Twelve of these 54 plants were dwarfs ranging in height from $22 \mathrm{~cm}$ to $35 \mathrm{~cm}$. The normal plants were at least one meter high, and most of them considerably taller. The ratio of normals to dwarfs was $4.5: 1$.

In 192141 of the $42 \mathrm{~F}_{3}$ families were grown, of which there were eight which carried both normal and dwarf plants only. Ratios of these eight families are shown in table 16, graded according to size of ratios.

\begin{tabular}{|c|c|c|c|}
\hline FAMILY & NORMALS & DWARFS & RATIO \\
\hline 149. & & & \\
\hline 10 & 49 & 9 & $5.4: 1$ \\
\hline 12 & 68 & 8 & $8.5: 1$ \\
\hline 5 & 53 & 5 & $10.6: 1$ \\
\hline 23 & 55 & 4 & $13.8: 1$ \\
\hline 11 & 59 & 4 & $14.8: 1$ \\
\hline 14 & 31 & 2 & $15.5: 1$ \\
\hline 7 & 64 & 4 & $16.0: 1$ \\
\hline 19 & 64 & 4 & $16.0: 1$ \\
\hline
\end{tabular}

In this case probably six families out of the eight belong to the ratio group $15: 1$. If two factors are responsible for the normal condition, as is suggested by the data in table 16 , it is not possible to account for the ratios as they stand. In the $F_{2}$ generation one dwarf plant out of 15 should 
have appeared instead of the two out of nine that did appear. No seed from dwarf plants was planted, so the history of these is lost. Seven out of 15 of the normal plants should have produced families carrying only normal offspring. As a matter of fact, 33 families out of 41 behaved in this manner, which is a much higher percentage than is expected. Of the families which carried both dwarfs and normals, one-half should show the ratio of $3: 1$, and the other half should produce normals and dwarfs in the ratio of $15: 1$. The actual results evidently do not accord at all well with the two-factor hypothesis suggested by the tabulation.

Data secured from the offspring of plants $140.1,15,17$ and 20 are not sufficient to warrant any attempt at explanation of the facts. The value these data have is to show the complicated nature of the problem and that conditions have arisen which apparently are not amenable to ordinary Mendelian interpretation.

\section{GENERAL DISCUSSION}

The families derived from family 140.10 are shown distributed in table 17 with reference to ratio classes. Less ample results from another cross of the same parentage, family 140.11 , were similar to those secured from family 140.10. Other results were secured from crosses of other parentage with data too scanty to have a positive bearing.

The ratios shown in table 17 (with the exception of the aberrant and unexplained ratio of $1: 29$ ) are all of frequent occurrence in Mendelian investigations. Moreover, the approximation of the observed to the calculated results are, in general, very close. While these facts are outstanding, it is nevertheless true that it has not been found possible to postulate a genotypic formula for the $F_{1}$ individual which will explain all of the resulting ratios. Any simple hypothesis should be able to accomplish this. The conclusion seems inevitable, then, that the results before us are not amenable to any simple explanation.

The presence of each of the two ratios, $55: 9$ and $63: 1$, according to ordinary Mendelian reasoning, affords ample justification for a three-factor hypothesis. The fact that both ratios are present contrary to any one conventional hypothesis does not lessen at all the probability that three factors are present having to do with normal and dwarf heights. On the contrary, the presence of both ratios acts cumulatively in this respect.

It will be worth while to discuss briefly the hypotheses suggested by the data. First, it may be assumed that three factors were present in the $F_{1}$ genotype, each responsible for normal height. The progenies in the $F_{2}$ generation should have consisted of normals and dwarfs in a 
TABLE 17

Distribution of families derived from family 140.10 , carrying normal and dwarf plants, with respect to various ratio classes. The $F_{1}$ individual (133.9.1) was of normal height. In each ratio normal plants are placed first.

\begin{tabular}{|c|c|c|c|c|c|c|c|c|c|c|c|c|}
\hline \multirow{2}{*}{ PARENTAL ORIGIN } & \multicolumn{12}{|c|}{ RATIO CLASSES } \\
\hline & $1: 0$ & $3: 1$ & $13: 3$ & 559 & $|15,1|$ & $63: 1 \mid$ & $0: 1$ & $|1: 3|$ & $|7: 9|$ & $1: 15$ & $|(1: 29)|$ & $1: 63$ \\
\hline $\begin{array}{l}F_{2} \\
140.10 \ldots \ldots \ldots \ldots \ldots\end{array}$ & & & & $1(96$ & :18) & & & & & & & \\
\hline $\begin{array}{l}F_{3} \\
149.42-119 \text { and } 152.8 \ldots \\
P=140.10 \text { of } 55: 9 \text { class }\end{array}$ & 36 & 13 & 5 & 15 & 7 & 2 & 0 & 0 & $1(27:$ & 49) 0 & - & 0 \\
\hline $\begin{array}{l}F_{i} \\
156.1-55 \ldots \ldots \ldots \ldots \\
P=149.64 \text { of } 15: 1 \text { class }\end{array}$ & 28 & 1 & 7 & 14 & 3 & 2 & & & & & & \\
\hline $\begin{array}{l}156.56-115 \ldots \ldots \ldots \\
P=149.65 \text { of } 1: 0 \text { class. }\end{array}$ & 58 & 0 & 0 & 0 & 0 & 2 & & & & & & \\
\hline $\begin{array}{l}156.142-161 \ldots \ldots \ldots \\
\mathrm{P}=149.77 \text { of } 3: 1 \text { class }\end{array}$ & 6 & 8 & 0 & 2 & 2 & 2 & & & & & & \\
\hline $\begin{array}{l}156.162-200 \ldots \ldots \ldots \\
P=149.78 \text { of } 1: 0 \text { class }\end{array}$ & 32 & 0 & 0 & 0 & 1 & 6 & & & & & & \\
\hline $\begin{array}{l}156.201-215 \ldots \ldots \ldots \\
P=149.98 \text { of } 55: 9 \text { class }\end{array}$ & 7 & 0 & 5 & 3 & 0 & 0 & & & & & & \\
\hline $\begin{array}{l}157.1-57 \ldots \ldots \ldots \ldots \\
P=152.8 \text { of } 7: 9 \text { class }\end{array}$ & 17 & 0 & 0 & 0 & 0 & 0 & 4 & 20 & 6 & 2 & 4 & 2 \\
\hline
\end{tabular}

$63: 1$ ratio instead of the $96: 18$ which did result. The theoretical distribution of families among the ratio classes, secured from planting a random sample of normal $\mathrm{F}_{2}$ plants, in comparison with observed results is shown as follows:

$\begin{array}{lcccccc}\text { Ratio classes........... } & 1: 0 & 3: 1 & 13: 3 & 55: 9 & 15: 1 & 63: 1 \\ \text { Theoretical........... } & 46 & 7 & 0 & 0 & 15 & 10 \\ \text { Observed............ } & 36 & 13 & 5 & 15 & 7 & 2\end{array}$

Agreement of observed and calculated results is far from satisfactory even ignoring the two ratio groups $13: 3$ and $55: 9$, while if the families in these two groups are distributed among the legitimate classes resulting from the hypothesis the variance would be still more marked, taking into account the disturbances which would result in the fulfillment of the ratio demands. Further, the ratio classes $1: 3,1: 15$ and $1: 63$, secured 
among the offspring of plant 152.8 can not be explained at all by the duplicate-factor hypothesis without assuming a complete "reversal of dominance."

Another hypothesis suggests itself. One may assume a factor $N$, responsible for normal height, dominant over other factors. Also there is a factor for dwarfness, $D$, which makes itself evident only in the presence of an activating factor, $A$. A little consideration will show that when an $F_{1}$ individual is heterozygous for the three factors, the $F_{2}, F_{3}$, and $F_{4}$ generations will result as shown in figure 2 .

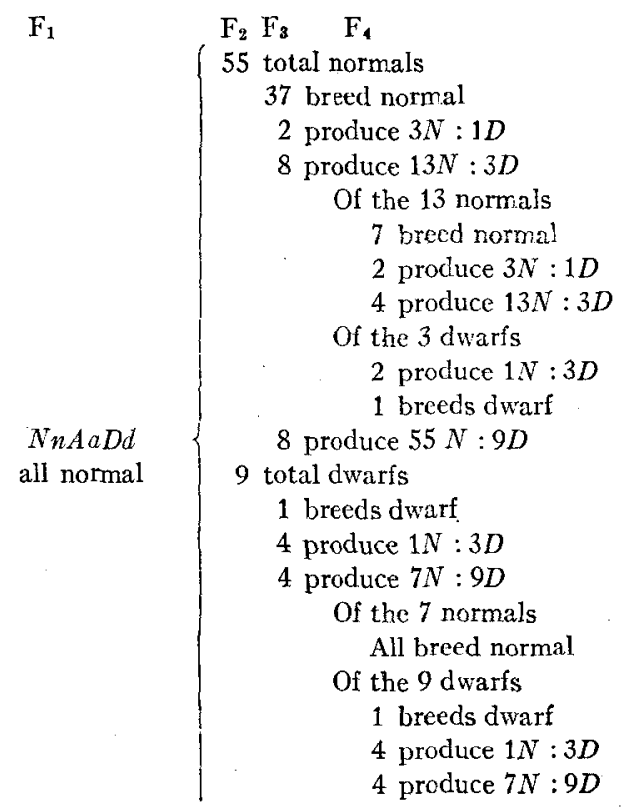

FIGURE 2.-Outline showing expected normal-and-dwarf composition of the offspring for three generations following an $F_{1}$ normal individual heterozygous in three factors according to the suggested hypothesis.

Reference to figure 2 shows the ratios $1: 0,3: 1,13: 3,55: 9,1: 3,7: 9$, and $0: 1$ of normals to dwarfs to result logically from such a genotype. All of these ratios were found in various families, as is seen by reference to table 17 , but the theory does not account for the ratios $15: 1,63: 1,1: 15$, and $1: 63$. The second theory accounts for a larger number of ratios than the first theory but this helps but little when one recognizes that there are certain outstanding facts which remain unaccounted for.

Assuming the second theory, one striking feature is the great excess of families carrying both normal and dwarf plants with the corresponding 
deficiency of families carrying normal plants only. In a total of 169 families presumed to carry only normal plants there were actually only 117 such families, a deficiency of over 30 percent.

If one assumes the second of the above theories as corresponding more nearly to the facts, it is evident that it must undergo some modification to meet the various demands. The necessary modification of the assumed genotype to produce the unexpected ratios of $15: 1$ and $63: 1$ is of a rather profound nature. As the deficient families are those expected to produce only normal offspring it is evident that it is in these genotypes that one must look for modifications. Assuming this theory to be the true one for the time being, any of the numerous normal-breeding genotypes may be taken for illustrative purposes. A zygote of the formula $N N A a D d$, when self-fertilized, would be expected to produce only normal plants. If families are to be produced from this genotype of the ratio of $63: 1$, one of the dominant factors for normal height would have to be modified to become a recessive factor, while the two other dominant factors, for dwarfness and for activation of dwarfness, would have to be modified so that they became responsible for normal height.

It would be a matter of considerable difficulty to prove that the foregoing hypothesis, with its attendant conditions, is correct. In the first place, assuming the theory outlined, there would be 19 different genotypes constituting the normal plants in the $\mathrm{F}_{3}$ generation, while the dwarf plants would be found to be of four genotypes. This being true, one would be able to pick out by progeny results only a very limited number of known genotypes to be used in genetical analysis. One of these would be $N n A a D d$ while another would be $N n A A D D$. If individuals carrying these two genotypes were crossed, 14 different genotypes would be expected among a sample of 16 offspring individuals. As only one $F_{1}$ individual results from each hybridization, the difficulties of the problem become sufficiently obvious.

Again, if this hypothesis is correct, an attempt at verification must take into account the possibility that a modified instead of an unmodified genotype is being used in test crosses. This may or may not make a difference. Also, in regard to any genotype selected for a test cross, there is a considerable chance that it will undergo modification while in use. As no knowledge of such a modification, aside from a consideration of the progeny, would be available and as the value of the test is dependent upon the distribution of the offspring, it is evident that many of the test crosses would be rendered nugatory. Judging by the number of deficient normal families indicated above, one could expect at least 30 percent of the test crosses to result quite inconclusively. 
Because of the uniqueness of the distributions of normals and dwarfs resulting in ratios inexplicable by any one hypothesis, and because of the irregular distribution of families producing the ratio, the testing of the suggested three-factor-modification hypothesis is of much importance in spite of the obvious difficulties. This work is being carried forward at the present time. If the work is carried out successfully.one should be able to demonstrate the probable composition of certain of the genotypes. Modification of these in a manner to produce the unexpected ratios as previously indicated could hardly be demonstrated directly, but if modified ratios continued to appear the corollary would be that they arose by reason of the postulated factor modification.

Assuming the genetic composition of the $\mathrm{F}_{3}$ generation to be as indicated in figure 2, it should not be difficult to isolate individuals with the formula NNAADD derived from individuals throwing 3 normals to $1 \mathrm{dwarf}$, of the formula $N n A A D D$. If such an individual be crossed to a sample of individuals derived from a plant producing a $7: 9$ ratio there should result in the $F_{2}$ generation families producing normals and dwarfs in the ratios and in the proportions indicated in table 18.

TABLE 18

Calculated distribution of ratios in $F_{2}$ families resulting from crossing the tester NNAADD with individuals of the indicated genotypes.

\begin{tabular}{|c|c|c|c|c|c|c|}
\hline & \multicolumn{3}{|c|}{ DWARFS } & \multicolumn{3}{|c|}{ NORMALS } \\
\hline & ${ }^{n n A A D D}$ & $\begin{array}{l}n n A a D D \\
* n A A D d\end{array}$ & $n n A a D d$ & $\begin{array}{l}\text { nnaaDd } \\
\text { nnAadd }\end{array}$ & $\begin{array}{l}\text { nnAAdd } \\
\text { nnaaDD }\end{array}$ & nnaadd \\
\hline $\begin{array}{c}\text { NNAADD } \\
\text { (Tester) }\end{array}$ & $3: 1$ & $\begin{array}{rr}\frac{1}{2} & 3: 1 \\
\frac{1}{2} & 13: 3\end{array}$ & $\begin{array}{rr}\frac{1}{4} & 3: 1 \\
\frac{1}{2} & 13: 3 \\
\frac{1}{4} & 55: 9\end{array}$ & $\begin{array}{ll}\frac{1}{2} & 13: 3 \\
\frac{1}{2} & 55: 9\end{array}$ & $13: 3$ & $55: 9$ \\
\hline
\end{tabular}

Of the genotypes to be tested shown in table 18 , only $n n A A D D$ and $n n A a D d$ would be known directly by the progeny ratios secured through self-fertilization.

Assuming the hypothesis suggested, one sees that if the gametes of the two normal individuals, $n n A A d d$ and $n n a a D D$ are brought together in hybridization, the entire $F_{1}$ progeny will consist of dwarf plants. In this connection it is of interest to recall the results secured by SAX (1921) in crossing two common wheat varieties, Bluestem and Amby. The resulting population of about 50 plants consisted entirely of sterile dwarfs. It would be necessary to assume, in this case, apparently, that the genotype of each variety carried a dominant factor for dwarfness ineffective phenotypically unless acting together in one genotype.

Genetics 9: My 1924 
ORIGIN OF THE FACTORS

In regard to the possible origin of the dwarf characters, discussion will be limited to the cereals. There is no evidence, one way or another, whether the factor for dwarfness in maize arose as a mutation at the time of observation or had been already carried in the genotype in a heterozygous condition, as is possible in a population of maize, for a long period without being made noticeable.

In the case of the self-fertilized cereals, wheat, oats and barley, the case is different, for the character in a homozygous condition would find little or no chance of surviving in the somatic form. In the case of the dwarf in oats, cited by WARBURTON (1919), there is little evidence that the dwarf appeared as the result of a cross one or two generations previous to the appearance of the dwarf. He states that while accidental crosses are common with oats in Idaho, all of the plants appearing in the family containing the dwarfs appeared to be of the Victory variety. It seems probable that the dwarf character resulted from a mutation occurring in the parent plant. If the dwarf appeared as the result of accidental crossing between two head-rows of the Victory oats, genotypically unlike, then the difficulty is only pushed back a few generations for a mutation would have to be postulated in one of the pure lines. In this case the mutation would probably have to be of a more complicated character if it were to be carried hidden in a biotype, for a normal homozygous plant carrying a factor or factors for dwarfness must also carry protective genes in the germ-plasm, perhaps in the nature of inhibitors.

It is difficult to believe, in the two cases cited by Stanton (1923), in view of evidence from other investigators, that the crosses made by him four and six generations previous to the appearance of the dwarfs had nothing to do with their becoming visible. At the same time it is difficult to understand the inhibiting mechanism of the genotype protecting homozygous dwarfs or those of a monohybrid ratio, although the phenomenon is not dissimilar from what seems to have occurred in my work where phenotypically normal plants evidently underwent a genotypical modification of a nature to produce dwarfs in place of the expected 100 percent normal offspring as instanced in the apparent deficiency of over 30 percent of normal plants.

In the case of the dwarf wheat plants found by Farrer (1898) and by RichaRDSON (1913) it is impossible to determine the number of the factors responsible for dwarfness. Judging by RICHARDSON's scant results only very few dwarfs appeared in comparison with normals, thus indicating an apparently complicated condition involving more than one factor. 
In the work detailed in this paper, normal-statured plants produced dwarfs of extreme habit as a portion of the progeny. It is difficult to believe that a phenotypically normal plant can carry such factors in its genotype and produce its normal growth. Something like this, however, must occur, for in this investigation some of the offspring of various, apparently normal, plants consisted of dwarfs, indicating that the parent genotype carried factors for dwarfness. We do not know, however, that the presence of the dwarf factor or factors in the genotype of certain of the plants did not have an effect upon the soma. In order to secure accurate information upon this point, it would be necessary to grow families of plants of known genotypes under comparable conditions so that morphological and yield comparisons could be made. A study of this kind would be of importance for it should throw light upon the possible effect upon the soma in maize, brought about by the considerable number of factors known to be carried by the genotype in an ordinarily recessive condition, injurious or even lethal when homozygous.

In this connection a point should not be overlooked which may have a bearing upon the problem. According to the investigation of SAX (1922), common wheat has three times the number of chromosomes found in Triticum monococcum and its genotype presumably is hexaploid. If the genotype of common wheat was built up in this manner from a more primitive type of wheat, evidently the factors would be triplicated so that there would be three factors for dwarfness in common wheat. Having three such factors, two of them might become modified in such a manner that they would produce dwarfness only in interacting and not act independently in this capacity.

The difficulty that arises here is to explain how the factors for dwarfness in a recessive condition - evidently they must have been originally in this condition-came to a dominant condition as they are found in the present investigation. There are various difficulties with the hexaploid theory. One is that dwarfness has never been reported in crosses with durum wheats. ${ }^{5}$ In this group of wheats one would expect to find two factors responsible for dwarfness. It is true, of course, that fewer crosses have been made between Triticum durum and $T$. vulgare than between varieties of the latter, and lessened fertility in the progeny of the interspecific crosses must also be considered. Also, speaking generally, one would expect to find many characters in $T$. vulgare based upon three factors in

\footnotetext{
5I take it that the "dwarfs" mentioned by MeIster (1922) in his crosses of common and durum wheat were merely the more heterozygous and sterile forms of something less than normal height found in the $\mathrm{F}_{2}$ generation.
}

GeNeTICs 9: My 1924 
the genotype, but up to the present time only a very few characters in wheat are determined by three factors. The best known is the red bran color which has been worked out by different investigators.

With the exception of the dwarf oats of WARBURTON (1919) dwarf characters in the self-fertilizing cereals which have been reported, have evidently become manifest only through crossing. According to current Mendelian belief the factor for dwarfness must have existed in the germplasm previous to the cross but was prevented from appearing by the lack of some necessary accessory factor or by the presence of some inhibiting factor or of some dominant normal factor acting inhibitorily. Evidently the dwarf factor arose at some time through mutation. In the case of maize this can happen and the character can be carried along from one generation to another apparently without interference to the continued propagation of the plant. In the self-fertilized cereals, however, such a condition is impossible and the phenotypical dwarf is immediately or soon eliminated. Knowing that factors for dwarfness have arisen in wheat from time to time, basing this knowledge upon results from certain crosses, it is very strange that the character for dwarfness has not made itself immediately manifest. Considering the close study that wheat has had by so many thousands of observers for so many years, it is almost certain that these dwarfs would have been observed and reported if they had come to expression in the soma.

These remarks are merely leading up to the question whether the germplasm of the self-fertilized cereals may not have some sort of a protective or self-regulating device whereby such injurious lethal or semi-lethal mutations as dwarfs are accompanied by other protective mutations. It is well known that maize carries lethal and malforming factors from one generation to another hidden by the dominancy of the normal or "wild" condition. Judging by the great rarity of mutations of this character in wheat, oats and barley, and by the comparative abundance of these characters in maize, one is tempted to believe that they appear less commonly in the normally self-fertilized cereals than in the open-fertilized maize. One of the answers to this suggestion is that in maize these lethal and malforming mutations may have arisen very gradually through hundreds or even thousands of years, and have been carried, perhaps as a continually increasing burden, up to the present time.

SUMMARY

From the original wheat crosses made in 1918, data have been secured for three and four generations. The $F_{1}$ individual was of normal height. 
In one series the $\mathrm{F}_{3}$ generation showed families with the following ratios of normal to dwarf plants: $1: 0,3: 1,13: 3,55: 9,15: 1$ and $63: 1$. One of the dwarf plants of this series of the $F_{2}$ generation produced families in the $\mathrm{F}_{4}$ generation, with ratios of normal to dwarf plants as follows: $1: 0,0: 1,1: 3,7: 9,1: 15$ and $1: 63$. In addition an aberrant ratio of $1: 29 \pm$ appeared.

These data necessitate some kind of a three-factor hypothesis, but no simple one has been devised to account for a genotype of the $F_{1}$ generation producing the various ratios which resulted.

It is suggested that a factor, $N$, is present for normal height dominant over other genotypic conditions. In addition two other factors would be assumed, $A$ and $D$, activating and dwarf, resulting in dwarfness when both are present in the absence of dominant $N$. From this there should result $55: 9$ normals to dwarfs, in the $\mathrm{F}_{2}$ generation. In the $\mathrm{F}_{3}$ generation normal and dwarf plants should produce families of normals to dwarfs as follows: $1: 0,3: 1,13: 3,55: 9,1: 3,7: 9$ and $0: 1$. These ratios were secured and also the additional ratios indicated above.

If it be assumed in connection with the foregoing hypothesis, that certain of the genotypes ordinarily producing plants of normal height become so modified that genes for dwarfness are changed to genes for normal, and vice versa, the facts may be accounted for.

Work is now in progress to test out the foregoing hypothesis so far as conditions permit. If the hypothesis suggested is the correct one, the labile condition of various genes in the genotype will, in itself, greatly handicap a demonstration of the hypothesis.

Attention is called to the comparative rarity of injurious or lethal characters of this nature, presumably arisen by mutation, found in selffertilized cereals, in comparison with their comparative abundance in maize. It is suggested, moreover, that a critical comparative study of families of different known genotypes with respect to effect on yield, brought about by presence or absence of dwarf factors in the hybrid wheat under investigation, might throw some light on the effect upon the soma of maize of the various recessive characters normally present, which are lethal or highly injurious when homozygous.

\section{LITERATURE CITED}

Babcock, E. B., and Ceausen, R. E., 1918 Genetics in relation to agriculture. xx $+675 \mathrm{pp}$. New York: McGraw-Hill Book Co.

Cook, O. F., 1915 Brachysm, a hereditary deformity of cotton and other plants. Jour. Agric. Res. 3: 387-399. Pls. 53-62.

Cutler, G. H., 1919 A dwarf wheat. Jour. Amer. Soc. Agron. 11: 76-78. 
East, E. M., and Hayes, H. K., 1911 Inheritance in maize. Connecticut Agric. Exp. Sta. Bull. 167, pp. 5-142. $25 \mathrm{pl}$.

EMERSON, R. A., 1911 Genetic correlation and spurious allelomorphism in maize. Nebraska Agric. Exp. Sta. Ann. Rep. 24: 59-90.

1916 A genetic study of plant height in Phaseolus vulgaris. Nebraska Agric. Exp. Sta. Res. Bull. 7, pp. 3-73.

Emerson, R. A., and Emerson, S. H., 1922 Genetic interrelations of two andromonoecious types of maize, dwarf and anther ear. Genetics 7: 203-236.

FARRER, WM., 1898 The making and improvement of wheats for Australian conditions. Agric. Gaz. New South Wales 9: 152-156. (Also see N. S. W. Dept. Agric. Misc. Pub. 206, 1898.)

Kempton, J. H., 1920 Heritable characters in maize. III. Brachytic culms. Jour. Heredity 11: $111-115.3$ pl

1923 Inheritance of dwarfing in maize. Jour. Agric. Res. 25: 297-322. 5 pl.

Meister, G., 1922 An experiment in studying a cross between distinct species. Tr. durum Dest.XTr. vulgare Vill. A preliminary communication. 24 pp. The Saratoff Exp. Sta. [Ln Russian with English summary.]

Mryazawa, B., 1921 Dwarf forms in barley. Jour. Genetics 11: 205-208. 1 pl.

NeEthling, J. H., 1917 A preliminary note on dwarfs appearing in Gluyas Early (wheat) hybrids. South African Jour. of Sci. 14: 540-547.

Richardson, A. E. V., 1913 Wheat and its cultivation. Victoria Dept. Agric. Bull. 22. pp. 115-116.

SAx, K., 1921 Sterility in wheat hybrids. I. Sterility relationships and endosperm development. Genetics 6: 399-416.

1922 Sterility in wheat hybrids. II. Chromosome behavior in partially sterile hybrids. Genetics 7: 513-552. 3 pl.

Stanton, T. R., 1923 Prolific and other dwarf oats. Dominant dwarfness observed in two oat crosses. Jour. Heredity 14: 301-305.

Tschermak, E. voN, 1912 Bastardierungsversuche an Levkojen, Erbsen und Bohnen, mit Rücksicht auf die Faktorenlehre. Zeitschr. indukt. Abstamm. u. Vererb. 7: 81-234.

VILMokin, Ph. DE 1913 Sur une race de blé nain infixable. Jour. Genetics 3: 67-76. 1 pl.

WALDRon, L. R., and Clark, J. A., 1919 Kota, a rust-resisting variety of common spring wheat. Jour. Amer. Soc. Agron. 11: 187-195. 1 pl.

Warburton, C. W., 1919 The occurrence of dwarfness in oats. Jour. Amer. Soc. Agron. 11: $72-76.1$ pl. 